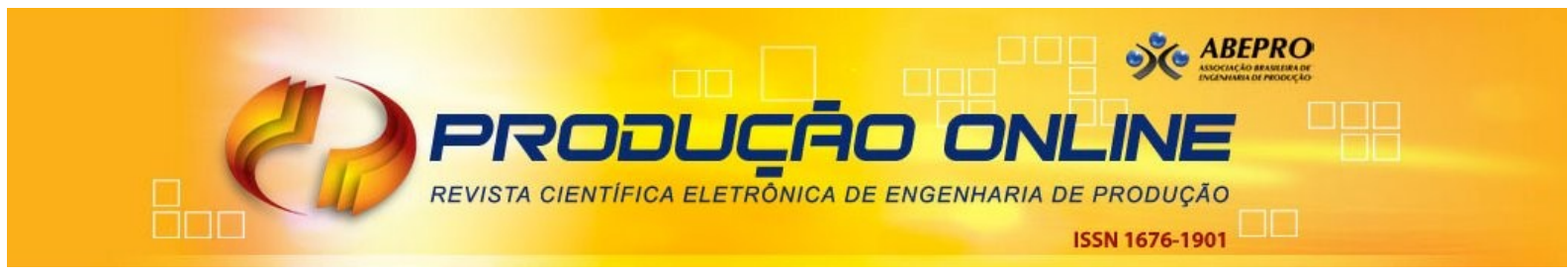

\title{
AVALIAÇÃO DE DESEMPENHO AMBIENTAL: ESTUDO DE CASO NA INDÚSTRIA PAPELEIRA
}

\section{ENVIRONMENTAL PERFORMANCE ASSESSMENT: A CASE STUDY IN THE PAPER INDUSTRY}

\author{
Paula Antonov*E-mail: paulaantonov@yahoo.com.br \\ Miguel Afonso Sellitto* E-mail: sellitto@unisinos.br \\ *Universidade do Vale do Rio dos Sinos - UNISINOS, São Leopoldo, RS
}

\begin{abstract}
Resumo: A inerente complexidade do tema desempenho ambiental torna difícil sua mensuração, remetendo a metodologias apoiadas na avaliação dos diferentes fatores capazes de influenciar o desempenho global. Associado ao desempenho ambiental está a necessidade de criar metodologias que permitam sua avaliação ao longo do tempo e facilitem a comparação entre operações de diferentes organizações ou de um mesmo grupo empresarial. A medição de desempenho ambiental surge em diversas fontes, no entanto, não se identificou uma metodologia dominante, que seja amplamente reconhecida e aceita pela comunidade acadêmica e pelas organizações. O objetivo geral deste artigo é testar um método de avaliação de desempenho ambiental em uma operação de manufatura, realizando um estudo de caso na indústria papeleira. Os resultados podem ser comparados com outras operações e serem usados, cumulativamente, em cadeias produtivas. Os objetivos específicos são: (i) modelar o desempenho ambiental da operação; (ii) usar o modelo para mensurar o desempenho; e (iii); interpretar os resultados e concluir. Inicialmente é feita uma revisão sobre temas relacionados à medição de desempenho ambiental, passando então a descrever a metodologia de pesquisa e os resultados da aplicação. O método compreende cinco construtos, avaliados por gestores e especialistas no processo segundo seu potencial de melhoria no desempenho ambiental: resíduos sólidos; efluentes líquidos; emissões atmosféricas; uso de recursos naturais e energéticos; e atendimento à legislação. Os construtos são apreendidos por indicadores qualitativos avaliados categoricamente. O resultado final é um índice de 76,69\%, que representa o desempenho ambiental da operação.
\end{abstract}

Palavras-chave: medição de desempenho ambiental, modelagem de desempenho ambiental, gestão ambiental, certificação ambiental, método SBP.

Abstract: The inherent complexity of environmental performance measurement makes it difficult to be gauged, sending it forth to methodologies supported on assessments of the various factors that could influence the overall performance. In association with the environmental performance lies the need to create methods that allows the assessment over the time in order to facilitate comparisons amongst different organizations or operations of a same company. Measurement of environmental performance comes from several sources thus a dominant approach widely recognized and accepted by the academic community and organizations can not be singled out. The purpose of this review is to test a method for assessing environmental performance in a manufacturer organization, performing a case study in the paper industry. The results can be compared with other operations and can be used, cumulatively, in supply chains. The specific objectives are (i) to model the environmental performance of the transaction, (ii) to use the model to measure performance, and (iii) to interpret the results and come to a conclusion. It begins with a review of the environmental performance measurement and then proceeds to the description of the research methodology and the results of its application. The method consists of five constructs, assessed by managers and processes experts according to their potential of environmental performance's improvement: solid waste, wastewater, gas emissions, deployment of natural resources, and legal compliance. The constructs are perceived by qualitative

Revista Produção Online. Florianópolis, SC, v.11, n. 4, p. 1059-1085, out./dez. 2011. 
indicators categorically evaluated. The final result is an index of $76.69 \%$, which represents the environmental performance of the operation.

Keywords: environmental performance measurement, modeling of environmental performance, environmental management, environmental certification, SBP method.

\section{INTRODUÇÃO}

Os efeitos da ação antrópica sobre o meio ambiente têm despertado o interesse de gestores e empreendedores por questões ambientais. Nas ultimas décadas, a sociedade passou a compartilhar preocupações acerca das conseqüências do consumo de recursos naturais e dos impactos causados por processamento e descarte, principalmente em atividades de produção. No foco dessa preocupação, estão as organizações industriais, cujas atividades são fonte de parte da degradação imposta ao meio ambiente (LUZ et al., 2006).

Diante da mobilização da sociedade, as empresas passaram a internalizar a questão ambiental nos seus negócios, passando a vê-la não mais como área de menor interesse, mas como área estratégica geradora de vantagem competitiva. Empresas têm adotado estratégias específicas para abordar a questão ambiental (MONTEIRO et al., 2003). Embora seu comportamento tenha sido ditado principalmente por imposições legais, tais como regulações, normas ou impostos, algumas empresas têm identificado potenciais benefícios advindos da adoção de um comportamento mais consciente e pró-ativo em relação ao ambiente (TYTECA, 1996). Várias linhas de ação têm sido adotadas. Alianças entre empresas com fins de co-processamento tendem a ser mais complexas, devido à necessidade de desenvolver relações inter-empresariais, mas no longo prazo têm apresentado bom resultado. Outras linhas de ação são a reciclagem de materiais e separação de resíduos, as tecnologias do tipo fim-de-linha, ou seja, instalações de tratamento de efluentes, que eliminam o ataque ao ambiente, mas não reduzem a geração do material contaminante. Já o reprojeto de processos e de produtos foca em prevenir o processo poluidor de ocorrer (MELNYK et al., 2003)

O Quadro 1 apresenta alguns dos aspectos que têm mudado com a maior inserção dos temas relacionados ao meio-ambiente nas estratégias de operação das empresas. 
Quadro 1 - Transição rumo a uma consciência ambiental em operações

\begin{tabular}{|l|l|}
\hline \multicolumn{1}{|c|}{ Visão Anterior } & \multicolumn{1}{c|}{ Visão da ecologia em operações } \\
\hline Domínio sobre a natureza & Harmonia com a natureza \\
\hline Meio ambiente natural é fonte de recursos & A natureza tem valor intrínseco, não é recurso \\
\hline $\begin{array}{l}\text { Crescimento na produção exige crescimento } \\
\text { no consumo de energia e recursos naturais }\end{array}$ & $\begin{array}{l}\text { Mais eficiência no uso de energia e recursos } \\
\text { naturais }\end{array}$ \\
\hline Recursos são infinitos & Recursos são limitados \\
\hline $\begin{array}{l}\text { Avanço tecnológico soluciona qualquer } \\
\text { problema }\end{array}$ & $\begin{array}{l}\text { Tecnologia não tem resposta para todos os } \\
\text { problemas }\end{array}$ \\
\hline Consumismo: o consumidor é o rei & $\begin{array}{l}\text { Simplificar as necessidades de consumo: reusar, } \\
\text { reciclar e reaproveitar bens }\end{array}$ \\
\hline
\end{tabular}

Fonte: Adaptado de Meyer (2000)

Em paralelo a essa evolução, tem-se verificado a necessidade de ferramentas que permitam a adequada e objetiva quantificação ou medição do desempenho das empresas no que diz respeito às questões ambientais (TYTECA, 1996). Indicadores de avaliação de desempenho ambiental têm sido desenvolvidos por diversas instituições, permanecendo, porém, lacunas nas metodologias até agora disponíveis na literatura. Geralmente, os sistemas de indicadores são focados em uma organização específica, dificultando a comparação com outras organizações, e freqüentemente dando mais importância aos aspectos da gestão interna do que aos efeitos ambientais propriamente ditos. Esses sistemas também são raramente pensados para uso ao longo da cadeia produtiva, no sentido de controle do desempenho ambiental tanto dos fornecedores como de transportadores e distribuidores de bens e prestadores de serviços associados ao produto (PEGADO et al., 2001).

Sistemas organizados de indicadores remetem ao conceito de desempenho ambiental. O objetivo geral deste artigo é testar um método de avaliação de desempenho ambiental em uma operação de manufatura. A questão de pesquisa foi: como avaliar o desempenho ambiental de uma operação de manufatura? 0 método de pesquisa foi o estudo de caso. Segundo Yin (2001), para questões de pesquisa do tipo como, o método de pesquisa do estudo de caso é indicado. Foi estudada uma empresa da indústria papeleira. Os objetivos específicos foram: (i) modelar o desempenho ambiental da operação; (ii) usar o modelo para mensurar o desempenho; e (iii) interpretar os resultados e concluir. São delimitações de 
pesquisa: a utilização de apenas um método, o nomeado pelo acrônimo SBP (SELLITTO et al., 2010); o uso dos construtos de Luz et al. (2006); e a aplicação única em uma operação de manufatura da indústria papeleira. As delimitações fazem com que a principal contribuição do artigo sejam os resultados específicos da empresa estudada. O método de pesquisa usado não permite generalizações na indústria.

Após a introdução, o artigo faz uma revisão dos temas relacionados à mensuração de desempenho ambiental e de métodos já propostos na literatura para esse fim, passando então a descrever a pesquisa realizada. A seguir, é feita uma discussão acerca dos resultados e do método e uma conclusão seguida de considerações sobre a continuidade da pesquisa.

\section{DESEMPENHO AMBIENTAL}

O desempenho ambiental é definido pela norma ISO 14001 como os resultados mensuráveis da gestão dos aspectos ambientais de uma organização, que podem ser confrontados com a política ambiental, os objetivos ambientais, as metas ambientais e outros requisitos de desempenho ambiental (ASSOCIAÇÃO BRASILEIRA DE NORMAS TÉCNICAS, 2004). Para Luz et al. (2006), o desempenho ambiental pode ser descrito como a informação analítica oferecida por um conjunto de indicadores que permite comparar entre si, ou contra uma referência externa, requisitos ambientais em setores de uma empresa, ou em empresas de uma indústria.

Azzone e Manzini (1994) argumentam que o desempenho ambiental deve ser uma parte estruturada do sistema de controle de gestão de uma empresa industrial, uma vez que podem influenciar receitas e despesas. As receitas podem aumentar quando a empresa segue uma estratégia verde, melhorando a compatibilidade ambiental dos produtos ou promovendo uma imagem de credibilidade, criada por tecnologias limpas. As questões ambientais também podem influenciar os custos. Por um lado, normas ambientais mais limitantes resultam em maiores custos de manufatura e administrativos. Por outro, programas focados em melhorar o desempenho ambiental podem reduzir resíduos e perdas, resultando em custos mais baixos. Para Seiffert (2009), a mensuração do desempenho ambiental 
pode orientar a formulação de estratégias para atingir a sustentabilidade produtiva. $A$ mensuração também oferece subsídios para comparação entre organizações. A avaliação periódica do desempenho da empresa permite monitorar o avanço da execução da estratégia e comparar o estágio de desenvolvimento com o de outras organizações.

De acordo com a norma ISO 14031, a avaliação de desempenho ambiental é um processo interno e uma ferramenta de gestão concebida para promover a gestão com informações confiáveis e verificáveis em base contínua para determinar se o desempenho está atingindo os objetivos definidos pela direção (ABNT, 2004). Para Jasch (2000), a avaliação de desempenho ambiental pode ser entendida como um processo contínuo de coleta e avaliação de dados e informações que pode fornecer uma avaliação do desempenho atual e tendências de desempenho. Para Pegado et al. (2001), a avaliação de desempenho ambiental permite medir e melhorar os resultados da gestão ambiental em uma organização ou atividade econômica. Entre as vantagens de sua aplicação, os autores assinalam três capacidades: (i) sintetizar e comunicar a informação; (ii) identificar áreas prioritárias de intervenção; e (iii) medir a distância em relação a metas ambientais impostas pela estratégia.

Duas abordagens distintas podem ser utilizadas para medir o desempenho ambiental: (i) medidas específicas de desempenho ambiental, construídas de acordo com as características e necessidades de uma determinada organização (como no caso da norma ISO 14031); (ii) medidas gerais de desempenho ambiental que podem ser utilizadas por diferentes organizações e em diferentes países (LUZ et al., 2006).

Para Pegado et al. (2001), a maioria dos artigos já publicados na área (até a data da pesquisa) tratava de aplicações em unidades industriais, trazendo especificidades do setor e da entidade alvo. Tais achados são apenas em parte, passíveis de transferência entre indústrias. Os autores argumentam que o desempenho ambiental está ligado à necessidade de criação de plataformas de trabalho comum entre organizações, sejam elas pertencentes ao mesmo grupo empresarial ou ao mesmo setor econômico. Esse fato se traduz na tentativa de criação de metodologias que permitam comparação objetiva e verificável dos 
resultados de desempenho intra e interorganizações, possibilitando práticas permanentes de benchmarking ambiental.

Segundo Kuhre (1998), a avaliação de desempenho ambiental poderá ser aplicada existindo ou não um sistema de gestão ambiental formal na empresa. Para Jasch (2000), uma organização com um Sistema de Gestão Ambiental (SGA) pode avaliar seu desempenho perante sua política ambiental, representada por meio de objetivos, metas e outros critérios de performance ambiental. Uma organização sem SGA pode usar avaliação de desempenho ambiental para ajudar na identificação dos seus aspectos ambientais, determinando quais serão tratados como significativos, definindo critérios para seu desempenho ambiental, e avaliando seu desempenho nesses critérios.

Empresas podem usar as especificações da norma ISO 14001 para avaliação e certificação de um SGA. Para Moura (2008), o crescente interesse em melhorar o desempenho ambiental tem levado empresas a certificarem-se por essa norma. Seiffert (2009) argumenta que as normas da série ISO 14000 procuram desenvolver uma abordagem organizacional de forma a promover uma gestão ambiental efetiva, que responda a exigências legais e de mercado. Os autores reforçam que a norma orienta o gerenciamento das atividades e dos aspectos ambientais decorrentes de processos, produtos ou serviços, e que o uso de um único sistema de gerenciamento reforça o enfoque no aprimoramento da conservação ambiental. Para Tibor e Feldman (1996), as normas da série ISO 14000 afetam os diversos aspectos da responsabilidade ambiental da gerência de uma empresa, ajudando a organização a abordar as questões ambientais de forma sistemática e a melhorar seu desempenho ambiental. Para Melnyk et al. (2003), entre outras características, as normas da série ISO 14000 facilitam o planejamento, o controle e a monitoração de políticas apropriadas de gestão ambiental.

\section{MENSURAÇÃO DE DESEMPENHO AMBIENTAL}

Diversos autores desenvolveram trabalhos ligados à medição de desempenho ambiental. Citam-se neste artigo o Ecoblock, apresentado em Pegado et al. (2001) e Melo e Pegado (2002) e o Prêmio Nacional da Qualidade em 
Saneamento (PNQS), promovido pela Associação Brasileira de Engenharia Sanitária e Ambiental.

O Ecoblock se baseia em indicadores para o cálculo de pressões ambientais, ou seja, qualquer fator de produção que represente potencial consumo de recursos naturais ou degradação ambiental. O método torna possível o transporte de preocupações ambientais ao longo da cadeia produtiva, contabilizando a totalidade das pressões ambientais de uma atividade, produto, serviço, cadeia ou processo (PEGADO et al., 2001).

Como aplicações, Melo e Pegado (2002) citam: (i) rotulagem ambiental de produtos ou serviços, indicando seu desempenho ambiental; (ii) simplificação da análise do ciclo de vida; (iii) descrição do desempenho ambiental de uma organização em um sistema de gestão ambiental; (iv) comparação do desempenho ambiental de diferentes atividades ou setores; ( $v$ ) controle do desempenho ambiental de fornecedores; e (vi) referência para eco-tributação.

O método usa cinco construtos: uso da água, utilização de materiais, uso do solo, emissões poluentes e aquecimento global. Os indicadores estão fortemente correlacionados com impactos globais, regionais ou locais, e são calculados por variáveis medidas e ponderadas por fatores de equivalência baseados em fatores técnicos ou regulamentares (MELO; PEGADO, 2001). O Quadro 2 mostra indicadores e critérios de cálculo.

Quadro 2 - Ecoblock: sistema de indicadores e critérios de cálculo

\begin{tabular}{|c|c|}
\hline Indicadores utilizados & Critérios para o cálculo dos indicadores \\
\hline Consumo de água & Proveniência e renovabilidade da origem da água \\
\hline Potencial de aquecimento global & $\begin{array}{l}\text { Emissões associadas à produção e consumo de } \\
\text { energia } \\
\text { Outras emissões de gases de efeito de estufa }\end{array}$ \\
\hline $\begin{array}{l}\text { Emissões poluentes (sólidas, líquidas, } \\
\text { gasosas) }\end{array}$ & Periculosidade equivalente \\
\hline Consumo de materiais & Renovabilidade da origem dos materiais \\
\hline Ocupação de área & Renovabilidade do uso do território \\
\hline
\end{tabular}

Fonte: Pegado et al.( 2001)

Como limitações, Melo e Pegado (2002) citam que o método não reflete aspectos específicos da gestão interna nem a perda de patrimônio ecológico, 
cultural e paisagístico, o mesmo ocorrendo para impactos locais ou específicos de atividades que oferecem dificuldades metodológicas complexas para padronização.

O Premio Nacional de Qualidade em Saneamento (PNQS) é promovido pela Associação Brasileira de Engenharia Sanitária, e busca "[...] estimular a prática de modelos gerenciais compatíveis com os melhores exemplos mundiais, por meio da promoção e do reconhecimento dos casos de sucesso que auxiliem no aprimoramento do setor de saneamento ambiental e no aumento da qualidade de vida da população" (PNQS, 2010). As três primeiras categorias de premiação (Níveis I, II e III) avaliam o sistema de gestão completo da organização. A quarta categoria é relativa à Inovação da Gestão em Saneamento, e avalia uma prática de gestão específica que tenha sido introduzida pela organização.

Os critérios de avaliação dos Níveis I, II e III do PNQS possibilitam julgar o grau de maturidade da adoção dos fundamentos da excelência pelas organizações, permitindo avaliar os processos gerenciais e os resultados organizacionais. O grau de maturidade é avaliado em três níveis, que correspondem a categorias de premiação distintas. Os fundamentos expressam os conceitos de pensamento sistêmico, aprendizado organizacional, cultura de inovação, liderança e constância de propósitos, orientação por processos e informações, visão de futuro, geração de valor, valorização das pessoas, conhecimento sobre o cliente e o mercado, desenvolvimento de parcerias e responsabilidade social. Esses fundamentos são incorporados no modelo de avaliação da gestão, que é composto por oito critérios. Sete critérios avaliam processos gerenciais: (i) Liderança, (ii) Estratégias e planos, (iii) Clientes, (iv) Sociedade, (v) Informações e conhecimento, (vi) Pessoas, e (vii) Processos. O oitavo critério avalia resultados organizacionais: (viii) Resultados (PNQS, 2010).

\subsection{0 método Sellitto, Borchardt e Pereira (SBP)}

O método usado neste artigo foi o SBP (SELLITTO et al., 2010). Para os autores, o termo desempenho ambiental é uma grandeza intangível, cuja complexidade intrínseca torna subjetiva sua mensuração. Sellitto e Ribeiro (2004) argumentam que como o acesso a essas grandezas não é unívoco: os conceitos subjacentes devem ser identificados até que se chegue a grandezas diretamente 
mensuráveis, ou que possam ao menos indiretamente ser aferíveis. Para os autores, como nem sempre se tem um modelo clara e unicamente estruturado, a representação do problema exige que o decisor use sua percepção, identificando e desdobrando os atributos que influenciam o objetivo em fatores e subfatores, até que a estrutura arborescente compreenda todos os aspectos importantes.

Sellitto e Ribeiro (2004) apresentam um método para a construção de indicadores baseado na teoria das medições e na filosofia da ciência, capaz de avaliar aspectos intangíveis complexos, tais como o desempenho ambiental. Luz et al. (2006) se baseiam no método multicriterial AHP (Analytical Hierarchical Process) para propor um método de medição de desempenho ambiental, que se utiliza de uma estrutura hierarquizada para relacionar a medição de indicadores ambientais e calcular a importância dos construtos que agregam estes valores, chegando a um índice que representa o desempenho global da operação. Para exemplificar e robustecer o método, os autores apresentam um estudo de caso de uma operação de manufatura de autopeças. Sellitto et al. (2008) testaram e robusteceram o método em um estudo de caso duplo onde foram realizadas medições de desempenho ambiental em operações de manufatura de pequeno porte, uma delas fabricante de materiais elétricos e a outra de peças forjadas e usinadas. Nesta pesquisa, o método de distribuição de importância entre os construtos foi aprimorado, evitando distribuições de importância fortemente desiguais. Em Sellitto et al. (2009a) são descritos dois casos de aplicação do método em operações de manufatura de grande porte: transformadores e hidrogeradores de alta potência e siderurgia. Sellitto et al. (2009b) apresentam dois casos em que o método foi testado em operações de fabricação de dispositivos eletrônicos e artefatos de plástico, ambas de pequeno porte. Kohl e Sellitto (2009) relatam um caso em que o método foi utilizado para avaliação de um operador logístico, testando-o em operações de serviços. Em Sellitto et al. (2010) é avaliado o desempenho ambiental de cinco operações: operação avícola, fabricação mecânica, fabricação de materiais elétricos, fabricação de rações e estamparia de aço.

O SBP consiste em um método de medição que objetiva capturar a complexidade do tema desempenho ambiental, modelando-o em uma estrutura concebida em três níveis hierárquicos. No topo encontra-se o termo teórico, sustentados por construtos latentes que, por sua vez, são explicados por 
indicadores. Os indicadores são variáveis manifestas presentes no nível inferior da estrutura, e podem ser calculados por mensuração direta ou por modelos específicos. No nível intermediário encontram-se os construtos, mensurados por composição dos indicadores que os sustentam. O nível superior da estrutura se vale da mensuração dos construtos para calcular o desempenho global (SELLITTO, 2005).

Os construtos e indicadores podem variar entre operações e ao longo do tempo, uma vez que a adequabilidade dos mesmos está ligada à capacidade de ajustar-se a diferentes realidades. Os construtos são avaliados segundo escalas de importância, conforme a tabela 1. Os valores atribuídos a cada classe permitem a mensuração da importância relativa de cada um dos construtos, fornecendo valores percentuais que posteriormente são comparados com o desempenho para obtenção das lacunas. Opcionalmente pode-se proceder à avaliação de importância também dos indicadores que compõem cada um dos construtos, contudo nas pesquisas realizadas com o uso do método nota-se uma tendência em distribuir importâncias idênticas. O desempenho dos indicadores é avaliado por julgamento categórico, segundo escalas de importância que variam entre ótimo e péssimo, conforme aponta a tabela 2 .

Tabela 1 - Distribuição de importância entre os construtos

\begin{tabular}{cc} 
Posição do construto & Pontuação \\
\hline Mais importante & 5 \\
Segundo mais importante & 4 \\
Terceiro mais importante & 3 \\
Quarto mais importante & 2 \\
Menos importante & 1
\end{tabular}

Fonte: Sellitto et al. (2008) 
Tabela 2 - Desempenho dos indicadores

\begin{tabular}{cc}
\hline Julgamento & Nota \\
\hline Ótimo & 1 \\
Bom & 0,75 \\
Médio & 0,5 \\
Ruim & 0,25 \\
Péssimo & 0
\end{tabular}

Fonte: Sellitto et al. (2008)

A média do desempenho atribuído a cada indicador é ponderada por sua importância relativa, fornecendo o desempenho do indicador. A soma dos desempenhos dos indicadores constitui o desempenho do construto que, somado aos demais construtos, compõe o índice de desempenho global, normalizado entre 0 e $100 \%$. A mensuração por escalas de julgamento exige menos esforço e recursos do que exigiria uma mensuração objetiva, baseada em variáveis de campo. Essa característica do método, aliado à simplicidade dos cálculos para obtenção dos índices, possibilita seu uso sem a necessidade de softwares específicos para tratamento de dados aleatórios ou instrumentação de campo, normalmente onerosos para a organização interessada na mensuração ambiental.

Como características do método pode-se citar: (i) flexibilidade; (ii) pequeno volume de dados e cálculos simplificados; (iii) permite a avaliação contínua ao longo do tempo; (iv) pode ser usado para comparação entre operações e; (v) permite a identificação de áreas prioritárias de intervenção. A flexibilidade da estrutura permite ajustes a novas circunstâncias operacionais e adaptação a novos conhecimentos e mudanças legais. O resultado da medição informa, segundo as circunstâncias apreendidas pelo modelo, as condições instantâneas da operação, que podem variar e evoluir ao longo do tempo (KOHL e SELLITTO, 2009).

o índice global normalizado, que oscila entre 0 e 100\%, facilita a comunicação dos resultados e a comparação entre operações. Uma das aplicações do método é seu uso como fonte de realimentação da estratégia ambiental, uma vez que à medida que a estratégia vai sendo executada, o modelo vai informando o avanço dos resultados. O método também possibilita a comparação entre operações similares e auxilia na tomada de decisões, direcionando o deslocamento de recursos alocados aos objetivos menos importantes para os mais importantes. $\mathrm{O}$ resultado 
final normalizado também é importante para a formação de uma série histórica de desempenho, capaz de refletir a trajetória do desempenho ambiental da operação (SELLITTO et al., 2010).

\section{A PESQUISA}

A pesquisa usou a metodologia SBP para avaliar o desempenho ambiental de uma operação de manufatura. O método foi aplicado em uma operação da indústria papeleira, que não possui um sistema de gestão ambiental estruturado, assim como não é certificada pelas normas da série ISO 14000. A empresa conta com cerca de 150 funcionários e atua na produção de papeis para uso industrial e para aplicações específicas.

Para a modelagem do desempenho ambiental da operação julgou-se adequada a utilização dos construtos já extraídos em pesquisa empírica por Luz et al. (2006): (i) situação dos resíduos sólidos; (ii) situação dos efluentes líquidos; (iii) situação das emissões atmosféricas; (iv) consumo de recursos naturais na operação; e (v) atendimento às legislações. Em sessões de grupo focado com nove executivos da empresa com atividades relacionadas à gestão ambiental, foram selecionados dezenove indicadores qualitativos capazes de explicar de forma abrangente os construtos ligados ao desempenho ambiental, sendo quatro relativos à geração de resíduos sólidos, dois à geração de efluentes líquidos, cinco ao consumo de recursos naturais, cinco às emissões atmosféricas e quatro ao atendimento à legislação. A Figura 1 apresenta a estrutura para modelagem do desempenho ambiental da operação de manufatura estudada, apresentando os construtos que explicam o termo teórico e os indicadores ligados a cada um dos construtos. 
Figura 1 - Estrutura do modelo de medição

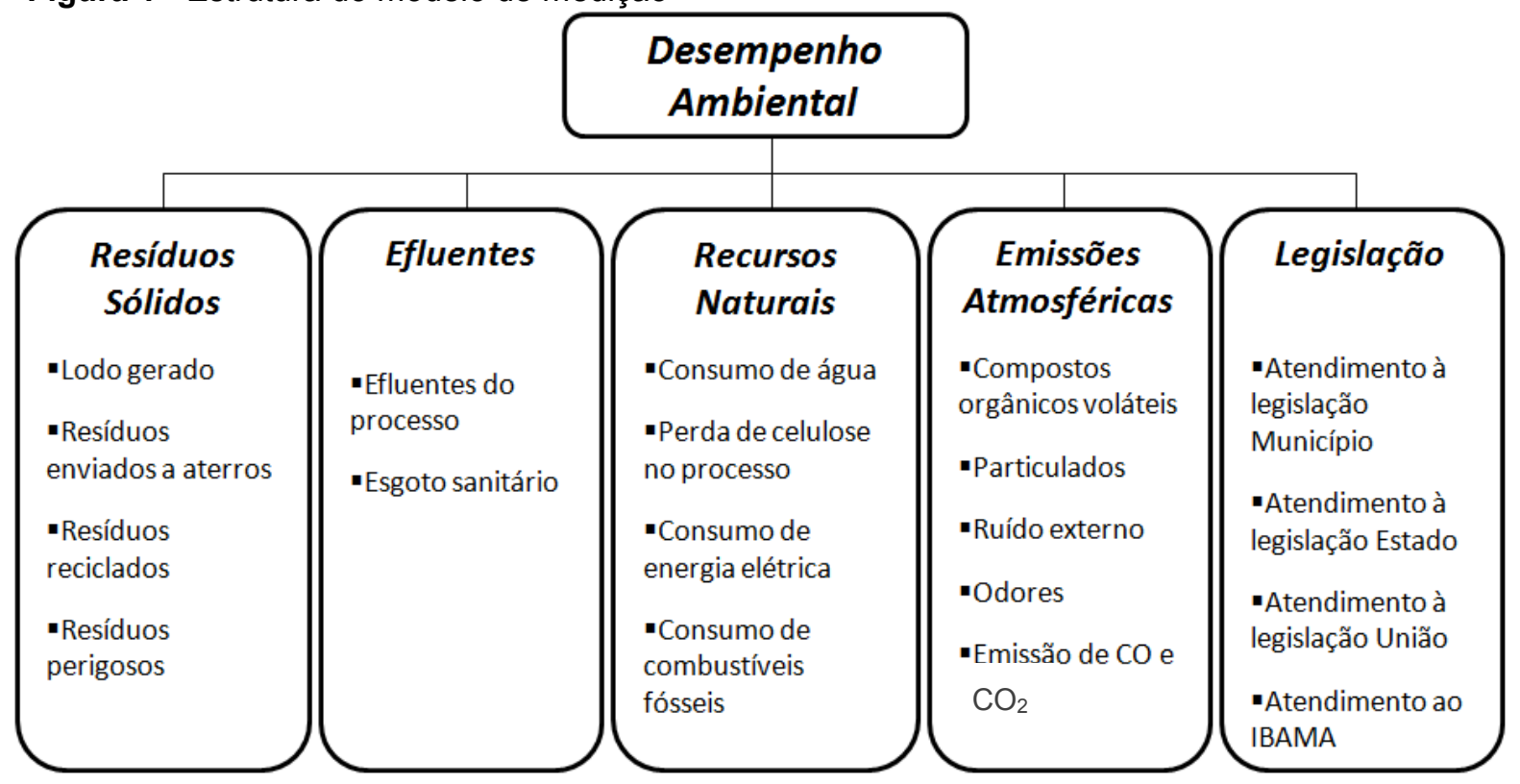

Fonte: Elaborada pelos autores

Com o auxílio de questionários objetivos, foi distribuída importância dentro do grupo de construtos. A distribuição foi feita pelos mesmos nove avaliadores, todos com conhecimento abrangente acerca do processo e de suas implicações ambientais. Foram usados os critérios da tabela 1. A Tabela 3 a seguir traz a pontuação atribuída pelos julgadores aos construtos, o vetor de prioridade resultante e a ordem de importância. 
Tabela 3 - Pontuação atribuída pelos respondentes

\begin{tabular}{|c|c|c|c|c|c|c|c|c|c|c|c|c|}
\hline \multirow{2}{*}{ Construtos } & \multicolumn{9}{|c|}{ Avaliadores } & \multirow{2}{*}{ Total } & \multirow{2}{*}{$\begin{array}{l}\text { Vetor de } \\
\text { prioridade }\end{array}$} & \multirow{2}{*}{ Ordem } \\
\hline & A & B & C & D & $E$ & $\mathbf{F}$ & G & $\mathbf{H}$ & $\mathbf{I}$ & & & \\
\hline Resíduos sólidos & 5 & 2 & 5 & 2 & 2 & 4 & 5 & 3 & 4 & 32 & 0,24 & $1^{\circ}$ \\
\hline Efluentes líquidos & 4 & 4 & 4 & 3 & 3 & 3 & 1 & 4 & 3 & 29 & 0,21 & $3^{\circ}$ \\
\hline Recursos naturais & 1 & 1 & 1 & 4 & 4 & 5 & 4 & 1 & 5 & 26 & 0,19 & $4^{\circ}$ \\
\hline Emissões atmosféricas & 2 & 3 & 2 & 1 & 1 & 2 & 2 & 2 & 2 & 17 & 0,13 & $5^{\circ}$ \\
\hline Atendimento à legislação & 3 & 5 & 3 & 5 & 5 & 1 & 3 & 5 & 1 & 31 & 0,23 & $2^{\circ}$ \\
\hline & & & & & & & & & otal & 135 & 1,00 & \\
\hline
\end{tabular}

Fonte: Elaborada pelos autores

O vetor de prioridade é calculado pela razão entre o somatório da importância atribuída ao construto e o somatório total, e reflete a importância relativa do construto. A ordem dos vetores de prioridade mostra a posição do construto em relação aos demais na avaliação dos julgadores, no que tange à sua capacidade de influenciar o desempenho ambiental da operação. O mesmo grupo julgou o desempenho dos indicadores, também com o auxílio de questionários objetivos e segundo a tabela 2. A Tabela 4 a seguir apresenta a pontuação atribuída pelos respondentes ao desempenho de cada um dos indicadores, sua média e o coeficiente de variação $(c v)$. 
Tabela 4 - Notas atribuídas aos indicadores

\begin{tabular}{|c|c|c|c|c|c|c|c|c|c|c|c|}
\hline \multirow{2}{*}{ Indicadores } & \multicolumn{9}{|c|}{ Avaliadores } & \multirow{2}{*}{ Média } & \multirow{2}{*}{$c v$} \\
\hline & A & B & C & D & $E$ & $\mathbf{F}$ & G & $\mathbf{H}$ & $\mathbf{I}$ & & \\
\hline Lodo gerado & 0,75 & 0,75 & 1 & 0,5 & 1 & 1 & 0,5 & 0,5 & 0,75 & 0,75 & 0,29 \\
\hline $\begin{array}{l}\text { Resíduos enviados a } \\
\text { aterros }\end{array}$ & 0,5 & 0,75 & 1 & 0,5 & 1 & 1 & 0,25 & 0,5 & 0,75 & 0,69 & 0,39 \\
\hline Resíduos reciclados & 0,75 & 0,75 & 1 & 0,75 & 0,75 & 0,75 & 0,75 & 0,5 & 0,75 & 0,75 & 0,17 \\
\hline Resíduos perigosos & 0,75 & 0,75 & 0,75 & 1 & 0,75 & 0,75 & 0,5 & 0,5 & 0,75 & 0,72 & 0,21 \\
\hline Efluentes do processo & 1 & 1 & 1 & 0,75 & 0,75 & 1 & 1 & 0,75 & 0,75 & 0,89 & 0,15 \\
\hline Esgoto sanitário & 0,75 & 0,75 & 0,75 & 0,5 & 0,75 & 0,75 & 1 & 0,75 & 0,75 & 0,75 & 0,17 \\
\hline Consumo de água & 0,25 & 0,5 & 1 & 0,75 & 0,25 & 0,5 & 0,25 & 0,5 & 0,25 & 0,47 & 0,56 \\
\hline $\begin{array}{l}\text { Perda de celulose no } \\
\text { processo }\end{array}$ & 0,5 & 0,75 & 0,75 & 0,5 & 0,75 & 0,5 & 0,5 & 0,25 & 0,75 & 0,58 & 0,30 \\
\hline $\begin{array}{l}\text { Consumo de energia } \\
\text { elétrica }\end{array}$ & 0,5 & 0,5 & 0,75 & 0,75 & 0,5 & 0,75 & 0,5 & 0,5 & 0,5 & 0,58 & 0,21 \\
\hline $\begin{array}{l}\text { Consumo de } \\
\text { combustíveis fósseis }\end{array}$ & 0,75 & 0,75 & 0,75 & 0,5 & 0,75 & 0,5 & 0,5 & 0,5 & 0,25 & 0,58 & 0,30 \\
\hline $\begin{array}{l}\text { Compostos orgânicos } \\
\text { voláteis }\end{array}$ & 0,75 & 0,75 & 1 & 0,5 & 0,75 & 1 & 0,5 & 0,75 & 0,5 & 0,72 & 0,27 \\
\hline Particulados & 0,5 & 0,75 & 1 & 0,5 & 0,75 & 0,5 & 0,75 & 0,5 & 0,75 & 0,67 & 0,27 \\
\hline Ruído externo & 0,5 & 0,25 & 1 & 0,5 & 0,75 & 0,5 & 1 & 0,75 & 0,5 & 0,64 & 0,40 \\
\hline Odores & 1 & 0,75 & 1 & 0,5 & 1 & 1 & 1 & 0,75 & 0,75 & 0,86 & 0,21 \\
\hline Emissões $\mathrm{CO}$ e $\mathrm{CO}_{2}$ & 0,75 & 0,75 & 0,75 & 0,5 & 1 & 1 & 0,75 & 0,5 & 0,5 & 0,72 & 0,27 \\
\hline $\begin{array}{l}\text { Atendimento à } \\
\text { legislação - Município }\end{array}$ & 1 & 1 & 1 & 1 & 1 & 1 & 1 & 0,75 & 1 & 0,97 & 0,09 \\
\hline $\begin{array}{l}\text { Atendimento à } \\
\text { legislação - Estado }\end{array}$ & 1 & 1 & 1 & 1 & 1 & 1 & 1 & 0,75 & 1 & 0,97 & 0,09 \\
\hline $\begin{array}{l}\text { Atendimento à } \\
\text { legislação - União }\end{array}$ & 1 & 0,75 & 1 & 1 & 1 & 1 & 1 & 0,75 & 1 & 0,94 & 0,12 \\
\hline Atendimento ao IBAMA & 1 & 1 & 1 & 1 & 1 & 1 & 1 & 0,75 & 0,75 & 0,94 & 0,12 \\
\hline
\end{tabular}

Fonte: Elaborada pelos autores

As médias das avaliações de desempenho dos indicadores fornecem subsídios para a priorização de ações de melhoria com foco no aumento do desempenho ambiental, indicando os pontos em que a operação possui os piores desempenhos na avaliação dos respondentes. A Figura 2 a seguir mostra os indicadores ordenados por sua média de desempenho. 
Figura 2 - Médias das notas atribuídas aos indicadores

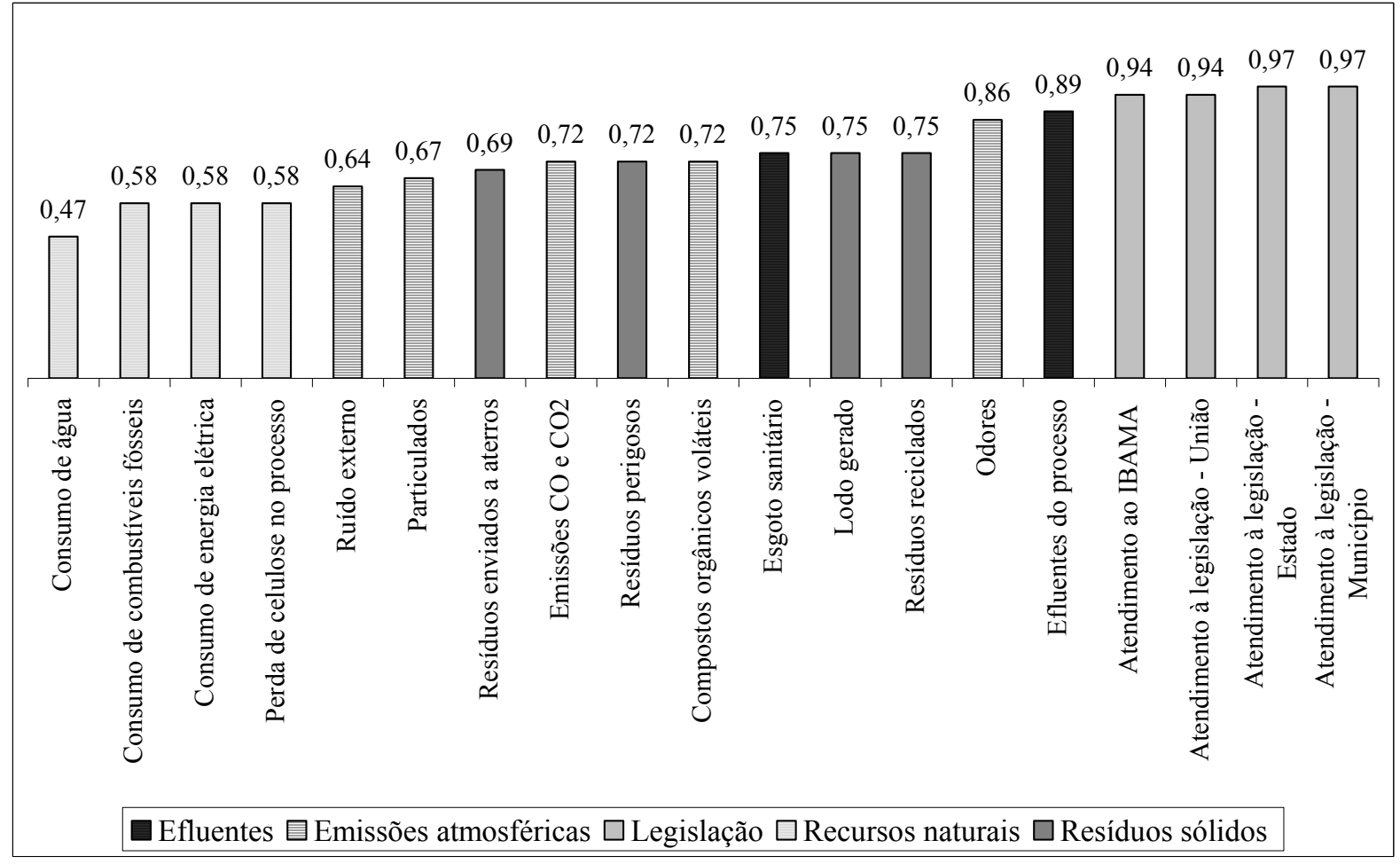

Fonte: Elaborada pelos autores

Os indicadores ligados ao construto Recursos Naturais apresentaram as médias de desempenho mais baixas, sendo a menor delas a relacionada ao consumo de água $(0,47)$, seguida da apresentada pelos indicadores consumo de energia elétrica, consumo de combustíveis fósseis e perda de celulose no processo $(0,58)$. Os indicadores relativos ao atendimento à legislação posicionaram-se como os de melhor desempenho, com médias bastante elevadas $(0,94$ e 0,97).

O coeficiente de variação $c v$ é calculado pela razão entre o desvio padrão e a média dos valores referentes à avaliação de desempenho do construto. Elevados cv podem indicar dúvida razoável entre os respondentes quanto à sua situação, o que gera disparidade de julgamento entre os respondentes. Essa disparidade pode estar ligada à falta de conhecimento acerca do fator em análise, ou mesmo pontos de vista discrepantes sobre o que seria um desempenho satisfatório para o item. Neste caso, mesmo que a média seja elevada, pode ser importante incluir estes indicadores de alta variabilidade em uma eventual reformulação da estratégia ambiental. A Figura 3 a seguir traz os indicadores em ordem decrescente de coeficientes de variação. 
Figura 3 - Coeficiente de variação das notas atribuídas aos indicadores

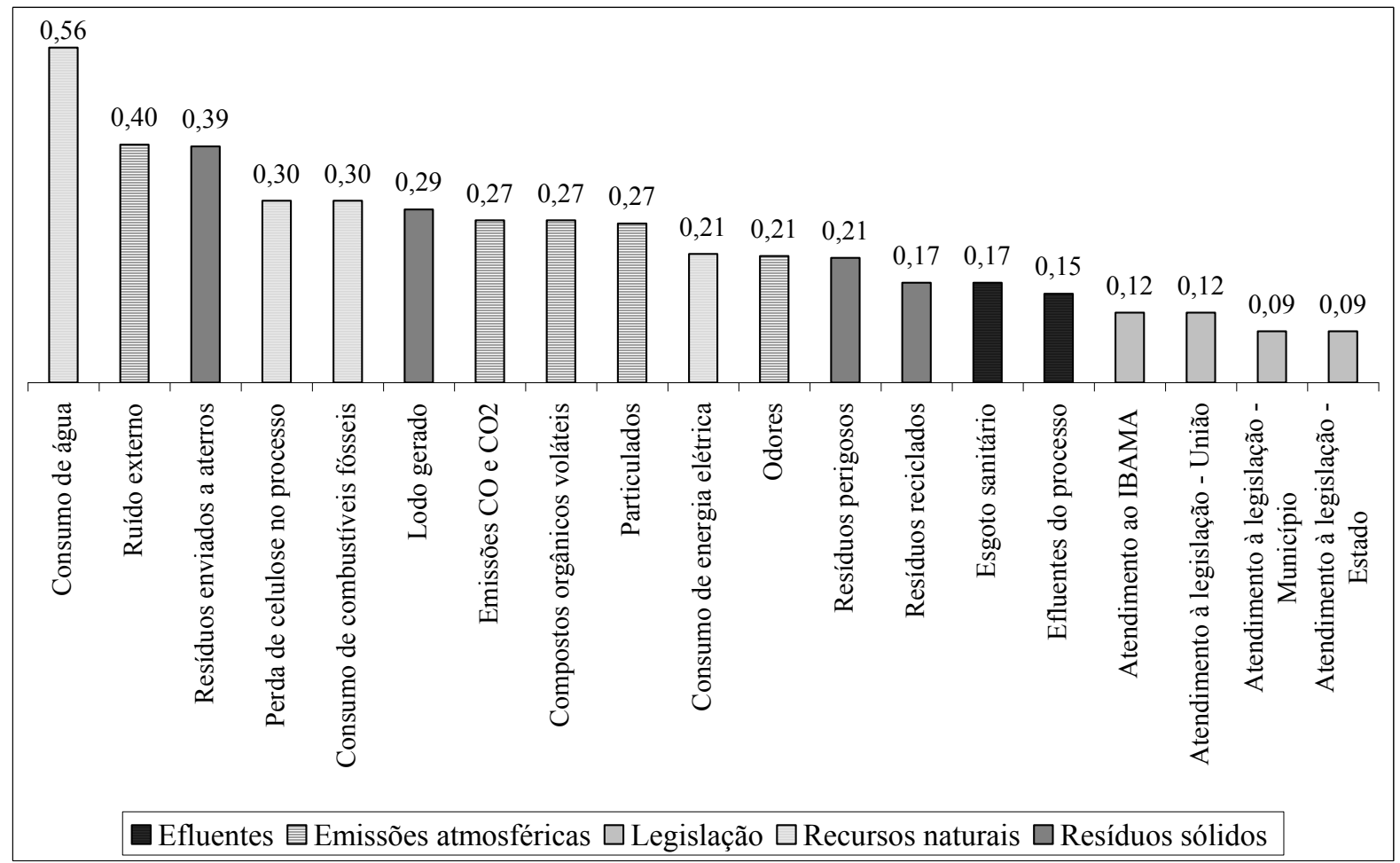

Fonte: Elaborada pelos autores

A Figura 3 mostra que o construto atendimento à legislação teve seus indicadores posicionados como os de menor coeficiente de variação. O gráfico, porém, não permite destacar um construto como de alta variabilidade, portanto a análise limita-se aos indicadores. O indicador consumo de água apresentou o maior coeficiente de variação $(0,56)$, seguido de ruído externo $(0,40)$ e resíduos enviados a aterros $(0,39)$.

A Tabela 5 a seguir traz a estrutura do modelo para a operação em foco e os resultados da medição. 
Tabela 5 - Modelo para medição do desempenho ambiental

\begin{tabular}{|c|c|c|c|c|c|c|}
\hline \multirow{2}{*}{$\begin{array}{l}\text { Construtos / } \\
\text { Importância }\end{array}$} & \multirow{2}{*}{ Indicadores } & \multirow{2}{*}{$\begin{array}{c}\text { Importância } \\
\text { do } \\
\text { Construto }\end{array}$} & \multirow{2}{*}{$\begin{array}{c}\text { Importância } \\
\text { do } \\
\text { indicador }\end{array}$} & \multicolumn{2}{|c|}{ Desempenho } & \multirow{2}{*}{ Lacuna } \\
\hline & & & & Indicador & Construto & \\
\hline \multirow{4}{*}{$\begin{array}{l}\text { Resíduos } \\
\text { sólidos } \\
24 \%\end{array}$} & Lodo gerado & 0,24 & $5,93 \%$ & $4,44 p p$ & \multirow{4}{*}{$17,28 p p$} & \multirow{4}{*}{$6,42 p p$} \\
\hline & $\begin{array}{l}\text { Resíduos enviados a } \\
\text { aterros }\end{array}$ & 0,24 & $5,93 \%$ & $4,12 p p$ & & \\
\hline & Resíduos reciclados & 0,24 & $5,93 \%$ & $4,44 p p$ & & \\
\hline & Resíduos perigosos & 0,24 & $5,93 \%$ & $4,28 p p$ & & \\
\hline \multirow{3}{*}{$\begin{array}{l}\text { Efluentes } \\
21 \%\end{array}$} & Efluentes do processo & 0,21 & $10,74 \%$ & $9,55 p p$ & \multirow{2}{*}{$17,60 p p$} & \multirow{2}{*}{$3,88 p p$} \\
\hline & Esgoto sanitário & 0,21 & $10,74 \%$ & $8,06 p p$ & & \\
\hline & Consumo de água & 0,19 & $4,81 \%$ & $2,27 p p$ & \multirow{4}{*}{ 10,70pp } & \\
\hline \multirow{3}{*}{$\begin{array}{l}\text { Recursos } \\
\text { naturais } \\
19 \%\end{array}$} & $\begin{array}{l}\text { Perda de celulose no } \\
\text { processo }\end{array}$ & 0,19 & $4,81 \%$ & $2,81 \mathrm{pp}$ & & \multirow{3}{*}{$8,56 \mathrm{pp}$} \\
\hline & $\begin{array}{l}\text { Consumo de energia } \\
\text { elétrica }\end{array}$ & 0,19 & $4,81 \%$ & $2,81 \mathrm{pp}$ & & \\
\hline & $\begin{array}{l}\text { Consumo de } \\
\text { combustíveis fósseis }\end{array}$ & 0,19 & $4,81 \%$ & $2,81 \mathrm{pp}$ & & \\
\hline \multirow{5}{*}{$\begin{array}{l}\text { Emissões } \\
\text { atmosféricas } \\
13 \%\end{array}$} & $\begin{array}{l}\text { Compostos orgânicos } \\
\text { voláteis }\end{array}$ & 0,13 & $2,52 \%$ & $1,82 p p$ & \multirow{5}{*}{$9,09 p p$} & \multirow{5}{*}{$3,50 p p$} \\
\hline & Particulados & 0,13 & $2,52 \%$ & $1,68 p p$ & & \\
\hline & Ruído externo & 0,13 & $2,52 \%$ & $1,61 \mathrm{pp}$ & & \\
\hline & Odores & 0,13 & $2,52 \%$ & $2,17 p p$ & & \\
\hline & Emissões $\mathrm{CO}$ e $\mathrm{CO}_{2}$ & 0,13 & $2,52 \%$ & $1,82 \mathrm{pp}$ & & \\
\hline \multirow{4}{*}{$\begin{array}{l}\text { Legislação } \\
23 \%\end{array}$} & $\begin{array}{l}\text { Atendimento à } \\
\text { legislação - Município }\end{array}$ & 0,23 & $5,74 \%$ & $5,58 p p$ & \multirow{4}{*}{$22,01 p p$} & \multirow{4}{*}{$0,96 p p$} \\
\hline & $\begin{array}{l}\text { Atendimento à } \\
\text { legislação - Estado }\end{array}$ & 0,23 & $5,74 \%$ & $5,58 p p$ & & \\
\hline & $\begin{array}{l}\text { Atendimento à } \\
\text { legislação - União }\end{array}$ & 0,23 & $5,74 \%$ & $5,42 p p$ & & \\
\hline & Atendimento ao IBAMA & 0,23 & $5,74 \%$ & $5,42 p p$ & & \\
\hline Totais & & & & $76,69 \%$ & & $23,31 \%$ \\
\hline
\end{tabular}

Fonte: Elaborada pelos autores

As importâncias relativas dos construtos são dadas pelos vetores de prioridade da Tabela 3. Optou-se por não distribuir importâncias relativas entre os indicadores, adotando importâncias uniformes dentro do construto. Essa importância é calculada pela divisão da importância atribuída ao construto pelo número de indicadores que o explicam.

O método SBP calcula o desempenho dos indicadores pela ponderação da média da pontuação de desempenho pela importância relativa. O somatório dos índices de desempenho dos indicadores fornece o desempenho do respectivo construto. As lacunas mostram a diferença entre a importância e o desempenho, 
representando o que o construto deixou de contribuir no cômputo do desempenho geral da operação.

\section{DISCUSSÃO}

A discussão aborda os resultados da medição de desempenho, a comparação com os resultados obtidos em pesquisas anteriores e o método aplicado. As considerações feitas estão embasadas em discussões surgidas durante a apresentação dos resultados para a empresa e em reunião de fechamento da pesquisa entre os gestores da empresa e os pesquisadores. Inicia-se pela análise dos resultados.

O resultado final da medição ficou em $76,69 \%$ do desempenho máximo que era possível. O alto desempenho já era esperado pelos gestores, que consideram a importância que a empresa dedica a atender a legislação como indicativo de respeito e valorização do meio-ambiente. A empresa atua em setor visado tanto por órgãos governamentais como pela sociedade em geral, devido às pressões ambientais que gera e o potencial poluidor de seus processos. As pressões provindas de grupos se tornam ainda maiores pelo fato de a empresa estar situada em região metropolitana, próxima de áreas com grande densidade populacional e industrial, e também por localizar-se às margens de corpo aquático relevante. Os construtos mais importantes foram Resíduos Sólidos (24\%) e Atendimento à Legislação (23\%), seguidos de Efluentes Líquidos (21\%), Recursos Naturais (19\%) e Emissões Atmosféricas (12\%).

O construto Resíduos Sólidos obteve importância relativa superior aos demais (24\%). Esta importância pode ser evidenciada pelas ações da empresa no sentido de conscientizar gestores e funcionários para a importância da gestão dos resíduos sólidos, sobretudo no que tange à coleta seletiva. A lacuna apresentada pelo construto $(6,42 p p)$ aponta oportunidades de melhoria, principalmente nos indicadores relacionados ao envio de resíduos a aterros e à geração de resíduos perigosos, que tiveram os piores desempenhos. Como alternativa, tem-se o coprocessamento em fornos de produção de clínquer, em cimenteiras da região, que podem receber resíduos de processo de papeleiras. A empresa envia a maior parte dos resíduos de processo para reciclagem, portanto o baixo desempenho no Revista Produção Online. Florianópolis, SC, v.11, n. 4, p. 1059-1085, out./dez. 2011. 
indicador pode ser atribuído aos resíduos provindos de setores administrativos e das atividades de manutenção.

O Atendimento à Legislação foi considerado o segundo construto mais importante (23\%). O empenho da empresa em manter $100 \%$ de atendimento à legislação contribui para esta avaliação, uma vez que o tema é tratado como diretriz estratégica e está presente na política da qualidade. Esse construto apresentou a menor lacuna $(0,96 p p)$, indicando que as ações no sentido de atender à legislação ambiental nos diferentes âmbitos - nacional, estadual, municipal e IBAMA - estão sendo efetivas e satisfatórias, segundo os respondentes.

A geração de grandes volumes de efluente provindos do processo pode explicar a importância atribuída ao construto Efluentes Líquidos (21\%), que obteve um índice próximo aos dois construtos anteriores. Apesar de, segundo os respondentes, os parâmetros de contaminação da água controlados pela empresa demonstrarem que o efluente é devolvido ao corpo aquático em melhor estado que o afluente coletado, o construto apresentou lacuna de 3,88pp. A lacuna foi atribuída pelos gestores consultados aos volumes elevados de efluentes tratados e liberados no corpo aquático.

A importância atribuída ao construto Recursos Naturais (19\%) está relacionada ao alto consumo desse tipo de recursos no processo. Esse construto apresentou a maior lacuna (8,56pp), demonstrando a percepção dos respondentes em relação à falta de ações efetivas para redução do consumo e desperdício desses recursos. O processo é altamente dependente do uso de celulose, que constitui a matéria-prima principal dos produtos fabricados. Ações no sentido de reduzir a perda de celulose no processo poderiam ser implementadas de imediato, reduzindo o uso do recurso. O consumo de combustíveis fósseis está ligado à energia utilizada na caldeira, para geração de vapor. Fontes renováveis de energia aparecem como alternativa para a redução do consumo deste recurso e o conseqüente aumento do desempenho do indicador. A substituição e manutenção periódica das instalações elétricas é uma ação que pode contribuir significativamente para a redução do consumo de energia elétrica.

O consumo de água apresentou a mais baixa média de avaliação de desempenho e o coeficiente de variação mais elevado entre todos os indicadores. A má avaliação está ligada ao uso de grandes volumes do recurso, exigido pelo 
processo de fabricação para abertura das fibras de celulose. A reutilização em ciclo fechado do efluente do processo pode ser uma alternativa, que além de reduzir o impacto da coleta de água do corpo aquático também poderia contribuir para a redução de custos com o tratamento do afluente coletado, já que o mesmo possui parâmetros de contaminação superiores ao do efluente devolvido.

Em último lugar na distribuição de importância ficou o construto Emissões Atmosféricas (12\%). Esse construto foi avaliado como menos importante por não representar um fator crítico para esse tipo de indústria, que exige poucos processos térmicos agressivos ao ambiente. O indicador ruído externo foi o que contribuiu de forma mais significativa para a lacuna de 3,50pp, sendo o segundo indicador com maior cv $(0,4)$. O cv elevado pode indicar percepção desigual dos respondentes quanto ao que seria um padrão aceitável de ruído emitido pela operação.

A comparação das lacunas entre a importância e o desempenho dos construtos permite identificar pontos onde os esforços de melhoria devem ser empregados. Esforços nestes pontos podem alavancar resultados ambientais. As lacunas apresentadas pelos construtos indicam que caso sejam necessários tradeoffs na disputa por recursos restritos, os construtos Recursos Naturais e Resíduos Sólidos devem ser priorizados. Atendimento à Legislação aparece como o construto onde são menores as necessidades de melhoria, podendo transferir recursos financeiros, materiais e/ou humanos aos demais.

Passa-se à comparação com resultados de pesquisas anteriores.

O desempenho ambiental da operação pode ser comparado com resultados de pesquisas semelhantes em manufatura, apresentadas em Luz et al. (2006), Sellitto et al. (2009a), Sellitto et al. (2009b), e Sellitto et al. (2010). Sellitto et al. (2010) argumentam que ainda não são prudentes generalizações a outras atividades que não as de manufatura. Optou-se então por não utilizar os resultados da pesquisa em serviços realizada por Kohl e Sellitto (2009) em um operador logístico. A Figura 4 apresenta o desempenho ambiental da operação atual em comparação com outras já mensuradas pelo método SBP. A figura inclui operações certificadas e não certificadas por normas da série ISO 14000. 
Figura 4 - Comparativo dos resultados com pesquisas anteriores

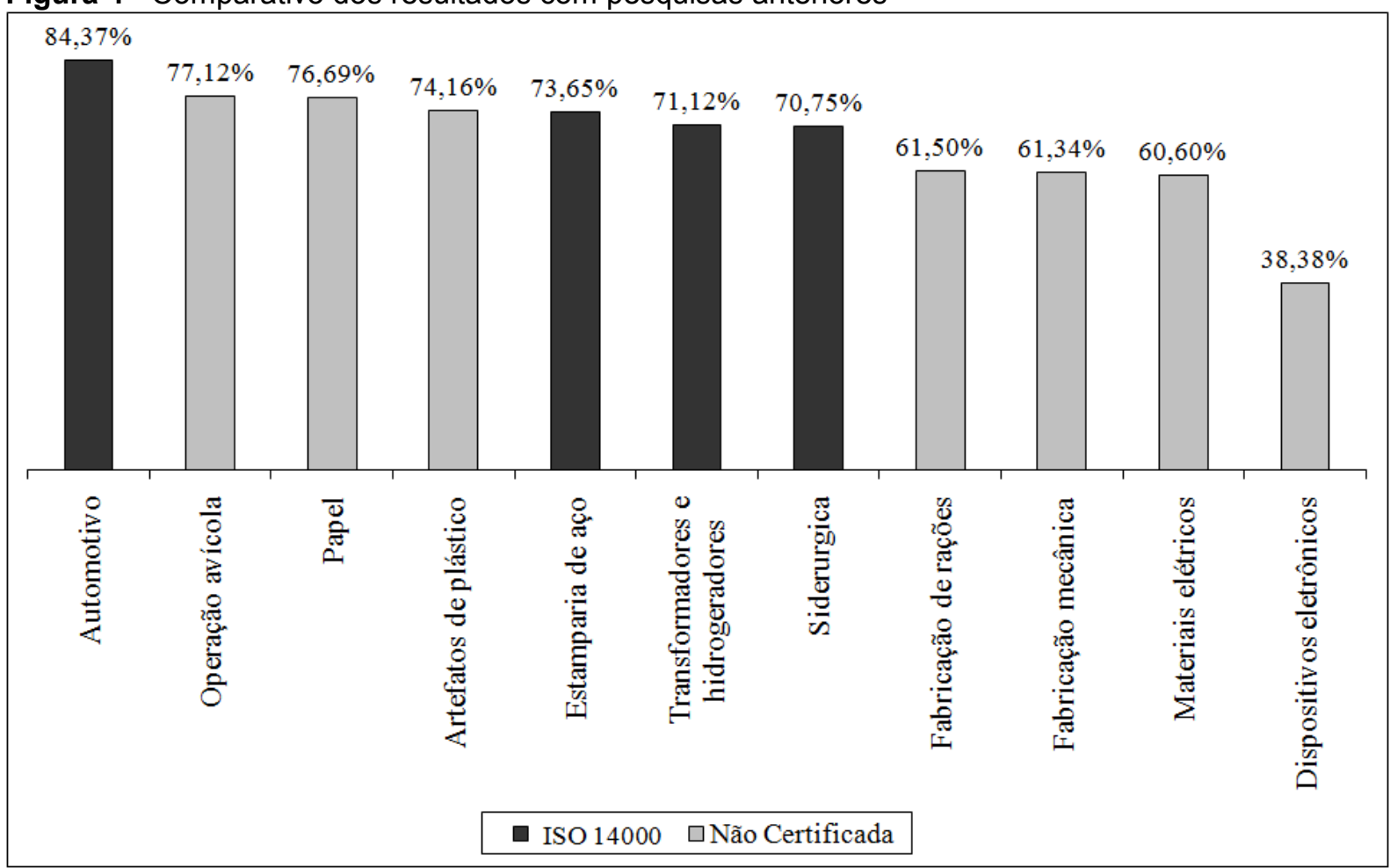

Fonte: Elaborada pelos autores

Os resultados sugerem que a certificação nas normas da série ISO 14000 não é mandatória para alto desempenho, pois há nesta faixa empresas certificadas e não certificadas. Práticas eficientes também podem ser desenvolvidas sem o uso referencial das normas. Empresas interessadas em manter um desempenho ambiental elevado podem adotar critérios tão rígidos quanto os impostos por esse tipo de norma, chegando a desempenhos semelhantes ou até superiores a empresas certificadas. Os resultados da comparação também permitem identificar que as empresas com mais baixo desempenho (inferior a 70\%) não possuem certificação. A explicação pode estar ligada ao efeito da aplicação da norma sobre o gerenciamento das atividades ligadas ao meio-ambiente, cujos requisitos tendem a elevar o padrão de desempenho a níveis compatíveis com exigências legais e de mercado. Em síntese, entre as empresas de alto desempenho há certificadas e nãocertificadas, mas entre as de baixo desempenho só há não certificadas. Esta parece ser uma contribuição da pesquisa, que poderá ser mais investigada em futuros projetos de pesquisa.

Passa-se ao método.

Revista Produção Online. Florianópolis, SC, v.11, n. 4, p. 1059-1085, out./dez. 2011. 
O método mostrou-se adequado à avaliação ambiental da operação estudada. A flexibilidade permitiu que a estrutura fosse modelada de acordo com a realidade da operação, incorporando os diferentes aspectos relevantes para a mensuração de seu desempenho. Um fator importante a ser considerado pela organização ao utilizar o método é a necessidade de revisões da estrutura do modelo sempre que ocorrerem alterações capazes de influenciar a determinação dos fatores onde o desempenho ambiental é desdobrado.

Nesta pesquisa optou-se por utilizar construtos já extraídos por especialistas em gestão ambiental. Para novas aplicações do método, sugere-se a eliminação do construto Atendimento à Legislação, já que o empenho da operação em atender à legislação influencia o desempenho de duas formas: ao ter seu desempenho considerado para o cálculo do índice global e ao agir sobre o desempenho dos outros construtos. Para Sellitto et al. (2010), ao menos em operações de manufatura, o construto poderia não ser mais investigado, já que as práticas nele inseridas podem ser consideradas como condição necessária e intermediária para os resultados finais, já apreendidos pelos demais construtos.

A mensuração utilizou-se de julgamento categórico. Esse tipo de medição, por um lado, é menos onerosa, pois não requer medição de grandezas de campo, como acontece quando se utilizam indicadores quantitativos. Por outro lado, avaliação por julgamento acarreta alguma subjetividade, segundo o avaliador e o momento. A utilização de indicadores quantitativos poderia fornecer resultados mais alinhados à realidade, desde que se evite utilizar apenas indicadores previamente existentes, ao invés de especificar aqueles que representam com maior fidelidade o desempenho ambiental da operação.

A aplicação do método não exigiu grandes esforços por parte da empresa. Os únicos custos relacionaram-se ao tempo despendido pelos participantes nas tarefas de seleção de construtos e indicadores e de avaliações de importância e desempenho. $\mathrm{O}$ uso de questionários objetivos para os julgamentos categóricos reduziu tempos e custos. Caso a empresa opte por realizar novas aplicações, serão necessários recursos para compilação dos dados e cálculo dos índices, que podem se utilizar de softwares já presentes na organização.

Os resultados obtidos podem ser utilizados para formar uma série histórica, descrevendo o desempenho ambiental da operação ao longo do tempo, e 
possibilitando a análise da eficácia de ações tomadas no sentido de melhorar o desempenho ambiental ou mesmo de mudanças na estratégia da empresa.

\section{CONSIDERAÇÕES FINAIS}

Esta pesquisa teve como objetivo geral testar um método de avaliação de desempenho ambiental em uma operação de manufatura na indústria papeleira. Os objetivos específicos foram: (i) modelar o desempenho ambiental da operação; (ii) usar o modelo para mensurar o desempenho; e (iii); interpretar os resultados e concluir. A pesquisa incluiu uma revisão bibliográfica, a descrição do método de pesquisa, seguidas de considerações sobre os resultados e sobre o método. $O$ método de pesquisa foi o estudo de caso. Como principal contribuição, têm-se os resultados específicos de mais um caso em operação de manufatura. Os resultados foram repassados à empresa, que pode usá-los em uma eventual reformulação de sua estratégia ambiental. Também podem ser usados em novas pesquisas, cujos objetivos sejam investigar as relações existentes entre desempenho ambiental e outras características e funções empresariais.

O método aplicado resultou em um modelo para avaliação do desempenho ambiental da operação estudada. Este modelo poderá ser utilizado pela empresa como direcionador das ações gerenciais em questões relacionadas ao meioambiente, orientando a tomada de decisões e indicando os resultados das estratégias implantadas.

Em comparação com as demais operações de manufatura já avaliadas pelo método SBP a operação da indústria papeleira obteve um desempenho elevado, sobretudo por não se tratar de empresa certificada pelas normas ISO 14000. A aplicação sistemática do método poderá trazer subsídios para a comparação com empresas semelhantes, pertencentes ao mesmo setor ou à mesma cadeia produtiva.

Uma das limitações do método está ligada à avaliação por julgamentos, dependente de fatores relativos ao julgador e à época de avaliação. Em termos gerais, essa avaliação pode ser influenciada pelo conhecimento e pelas crenças dos julgadores acerca dos itens em julgamento. É esperado que em um grupo significativo de respondentes nem todos tenham o mesmo nível de conhecimento Revista Produção Online. Florianópolis, SC, v.11, n. 4, p. 1059-1085, out./dez. 2011. 
sobre todos os fatores avaliados. Outra limitação está no fato de basear-se no julgamento de gestores e especialistas no processo, expostos a pressões para a elevação dos índices de desempenho. Essas pressões podem influenciar o julgamento quando incidem sobre o desempenho em avaliação, no caso o desempenho ambiental.

Como continuidade, propõe-se a comparação de resultados de operações com base em critérios capazes de influenciar o desempenho ambiental, tais como a localização geográfica (proximidade de centros urbanos), desenvolvimento da região onde a operação se encontra ou porte da organização. Também se propõe uma pesquisa com maior volume de casos, incluindo empresas com e sem certificação, de forma a confirmar ou não a hipótese inicial de que empresas de alto desempenho ambiental podem ou não ter certificação, mas empresas sem certificação terão baixo desempenho.

\section{REFERÊNCIAS}

ASSOCIAÇÃO BRASILEIRA DE NORMAS TÉCNICAS. NBR ISO 14001: sistemas de gestão ambiental: especificação e diretrizes para uso. Rio de Janeiro: ABNT, 1996. $48 \mathrm{p}$.

ASSOCIAÇÃO BRASILEIRA DE NORMAS TÉCNICAS. NBR ISO 14031: gestão ambiental - avaliação de desempenho ambiental: diretrizes. Rio de Janeiro: ABNT, 2004.

AZZONE, G.; MANZINI, R. Measuring strategic environmental performance.

Business Strategy and the Environment, v.3, n.1, p.1-14, 1994.

JASCH, C. Environmental performance evaluation and indicators. Journal of Cleaner Production, v.8, n.1, p.79-88, 2000.

KOHL, C.; SELLITTO, M. Avaliação do desempenho ambiental de um operador de serviços logísticos por indicadores categóricos. Estudos Tecnológicos, v.5, n.3, p.284-301, 2009.

KUHRE, W. ISO 14031: environmental performance evaluation (EPE): practical tools techniques for conducting an environmental performance evaluation. Upper Saddle River: Prentice Hall, 1998.

LUZ, S.; SELLITTO, M.; GOMES, L. Medição de desempenho ambiental baseada em método multicriterial de apoio à decisão: estudo de caso na indústria automotiva. Gestão \& Produção, v.13, n.3, p.557-570, 2006. 
MELNYK, S.; SROUFE, R.; CALANTONE, R. Assessing the impact of environmental management systems on corporate and environmental performance. Journal of Operations Management, v.21, n.3, p.329-351, 2003.

MELO, J.; PEGADO, C. 2002. Ecoblock: A method for integrated environmental performance evaluation of companies and products (construction case-study). In: INTERNATIONAL CONFERENCE ON ECOBALANCE, 5, 2002, Tsukuba, Japão, 2002. Anais... The Society of Non-traditional Technology, Tsukuba.

MEYER, M. Gestão ambiental no setor mineral: um estudo de caso. Florianópolis: UFSC, 2000. Dissertação (Mestrado em Engenharia da Produção) - Universidade Federal de Santa Catarina, Florianópolis, 2000.

MONTEIRO, P.; CASTRO, A.; PROCHNIK, V. A mensuração do desempenho ambiental no Balanced Scorecard e o caso da Shell. In: ENCONTRO NACIONAL SOBRE GESTÃO EMPRESARIAL E MEIO AMBIENTE, 7 , 2003. Anais...São Paulo: ENEGEMA, 2003.

MOURA, L. Qualidade e gestão ambiental: sugestão para a implantação das normas ISO 14.000 nas empresas. 5. ed. São Paulo: Juarez de Oliveira, 2008.

PEGADO, C.; MELO J.; RAMOS, T. Ecoblock: método de avaliação do desempenho ambiental. In: CONGRESSO NACIONAL DE ENGENHEIROS DO AMBIENTE, 2001, Lisboa. Anais... Lisboa: APEA, 2001.

PNQS: Guia do Prêmio Nacional de Qualidade em Saneamento. Belo Horizonte : ABES, 2010. Disponível em: < http://www.pnqs.com.br/vector/arquivos/116.pdf>. Acesso em: 20 jun. 2010.

SEIFFERT, M. ISO 14001 Sistemas de gestão ambiental: implantação objetiva e econômica. 3. ed. São Paulo: Atlas, 2009.

SELLITTO, M. Medição e controle de desempenho estratégico em sistemas de manufatura. 2005. Tese (Doutorado em Engenharia de Produção). Escola de Engenharia, UFRGS, Porto Alegre.

SELLITTO, M.; BORCHARDT, M.; PEREIRA, G. Avaliação de desempenho ambiental em duas operações de fabricação de grande porte. In: ENCONTRO NACIONAL DE ENGENHARIA DE PRODUÇÃO, 29, 2009, Salvador. Anais... Rio de Janeiro: ABEPRO, 2009a.

SELLITTO, M.; BORCHARDT, M.; PEREIRA, G. Avaliação de desempenho ambiental em duas operações de fabricação de pequeno porte. In: SIMPÓSIO DE ENGENHARIA DE PRODUÇÃO, 16 , 2009, Bauru. Anais... SIMPEP, 2009b.

SELLITTO, M.; BORCHARDT, M.; PEREIRA, G. Avaliação de desempenho ambiental em duas operações de manufatura. In: ENCONTRO NACIONAL DE ENGENHARIA DE PRODUÇÃO, 28', 2008, Rio de Janeiro. Anais... Rio de Janeiro: ABEPRO, 2008. 
SELLITTO, M.; BORCHARDT, M.; PEREIRA, G. Modelagem para avaliação de desempenho ambiental em operações de manufatura. Gestão \& Produção, v.17, n.1, p.95-109, 2010.

SELLITTO, M.; RIBEIRO, J. Construção de indicadores para avaliação de conceitos intangíveis em sistemas produtivos. Gestão \& Produção, v.11, n.1, p.75-90, 2004.

TIBOR, T.; FELDMAN, I. ISO 14000: um guia para as normas de gestão ambiental. São Paulo: Futura, 1996.

TYTECA, D. On the Measurement of the Environmental Performance of Firms- A Literature Review and a Productive Efficiency Perspective. Journal of

Environmental Management, v.46, n.3, p.281-308, 1996.

VERDUM, V.; SELLITTO, M. Avaliação de desempenho energético em uma instituição de ensino. Revista Liberato, Novo Hamburgo, v.10, n.1, p.15-33, 2009.

\section{RECONHECIMENTOS}

Agradece-se à empresa e aos executivos que colaboraram para a realização da pesquisa. Esta pesquisa foi integralmente financiada pelo CNPq.

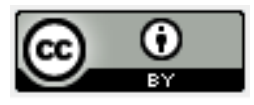

Artigo recebido em 13/07/2010 e aceito para publicação em 10/04/2011. 